\title{
Control Type Code
}

National Cancer Institute

\section{Source}

National Cancer Institute. Control Type Code. NCI Thesaurus. Code C93544.

A coded value specifying the kind of comparison or comparator against which another entity is evaluated. 